\title{
The effect of hemiplegia on blood pressure measurement in the elderly
}

\author{
R. Dewar, D. Sykes, E. Mulkerrin, F. Nicklason, D. Thomas and R. Seymour \\ University Department of Geriatrics and ${ }^{1}$ Department of Medicine, Cardiff Royal Infirmary, Newport \\ Road, Cardiff CF2 ISZ, UK
}

\begin{abstract}
Summary: The blood pressure in both arms of 103 unselected hemiplegic patients was measured using a random-zero sphygmomanometer. Although for the whole sample the mean blood pressure in the paretic and unaffected arm was similar, a significant difference was found when the patients were subdivided according to the tone of the arm. The blood pressure was higher in paretic arms of patients with a spastic stroke and lower in the affected arm if the tone was flaccid. No other characteristics were associated with significant blood pressure differences, so that the findings appear to be directly related to changes in muscle tone. After a stroke the blood pressure should always be measured in the unaffected arm because changes in tone make measurements unreliable.
\end{abstract}

\section{Introduction}

It has been shown that control of hypertension is important in the secondary prevention of strokes. ${ }^{1,2}$ It is therefore important to measure the blood pressure accurately in patients who have had a stroke. Advice has been given to take the blood pressure in the non-stroke arm, ${ }^{3}$ but there is conflicting evidence on the effects of a hemiparesis on blood pressure measurement with reports of a higher ${ }^{4,5}$ or a lower ${ }^{6}$ blood pressure in the affected arm. This study was designed to determine whether there is a clinically important difference in blood pressure, measured with a sphygmomanometer, between the stroke and non-stroke arms in hemiplegic patients. It was also designed to provide pointers to possible mechanisms.

\section{Materials and methods}

Hemiplegic patients were recruited to the study from assessment, rehabilitation and continuing care geriatric wards. A history was taken and examination performed by a doctor not involved in other aspects of the study. The date of the last stroke and the power, tone and mid-upper arm circumference of both arms were recorded. A six-point grading of power was used $(0 / 5 \text { to } 5 / 5)^{7}$

Correspondence: R. Dewar, M.R.C.P.(UK), West Wales General Hospital, Carmarthen, Dyfed, SA31 2AF, UK. Accepted: 24 February 1992 and tone was graded as normal, spastic or flaccid. If tone or power varied throughout the limb, that of the biceps muscle was recorded. The difference it mid upper-arm circumferences was used as afo index of wasting of the limb.

Blood pressure was measured supine after five minutes rest using a Hawksley 'random-zero' sphygmomanometer and the method recommended by the British Hypertension Society. Phase V of the Korotkoff sounds was used for the diastolic reading. In each patient, the arm used for initial measurement was randomly allocated (right or left) and three recordings of blood pressure made. The cuff was transferred to the other arm for the next three measurements and a final three recordings were taken on the initial side. All nine measurements were made by a single observer.

The mean for each set of three blood pressures was calculated ( $X_{1}, Y$ and $X_{2}$, respectively) for each patient and used for the further analysis. The last two groups of readings were used to examine the difference in blood pressure between the hemiplegic and unaffected ('normal') arms. The differences in blood pressure between arms $\left(X_{2}-Y=A\right)$ and between the two sets of measurement from one arm $\left(X_{2}-X_{1}=B\right)$ were then calculated for each subject and compared. The blood pressures were normally distributed and therefore a parametric statistical analysis was performed (paired $t$-test).

The mean blood pressure of the normal and paretic arms were compared for whole samples and then they were stratified for age, sex, time from last stroke, arm affected, power, wasting and tone. 
One hundred and three patients ( 65 female) aged 59-95 years (mean age 77) were studied. The hemiplegia (right-sided in $52 \%$ ) had occurred between one week and 8 years previously (mean 41 weeks). The affected arm was spastic in 41, flaccid in 56 and tone was normal in six patients. Power was graded as $0 / 5$ in $45,1 / 5$ in $21,2 / 5$ in $14,3 / 5$ in 11 and $4 / 5$ in 12 . The mid upper-arm circumference of the paretic arm was more than $1 \mathrm{~cm}$ smaller in 30 patients.

\section{Results}

Although there was a significantly greater $(P<0.001)$ mean difference in blood pressure between arms (systolic $11.2 \mathrm{mmHg}$, diastolic $9.4 \mathrm{mmHg}$ ) compared to that between two readings on a single arm $(6.2$ and $5.5 \mathrm{mmHg})$, the mean systolic and diastolic blood pressures of the normal (138/73 mmHg) and paretic arms (136/ $72 \mathrm{mmHg}$ ) were similar. The systolic and diastolic blood pressure readings are shown in Tables I and II, respectively.

When the hemiplegic group was sub-grouped according to tone, the measured blood pressure of those with a flaccid arm was significantly lower in the paretic arm $(135 / 68 \mathrm{mmHg})$ compared to the unaffected limb (140/74 $\mathrm{mmHg})$. There was a mean difference of $-5.7 \mathrm{mmHg}(95 \%$ confidence limits (CL) -2.7 to -8.7 ) for the systolic reading and $-6.0 \mathrm{mmHg}(-3.4$ to -8.6$)$ for the diastolic pressure. Conversely, in patients with a spastic stroke, the blood pressure was significantly higher in the paretic arm $(138 / 76$ vs $132 / 71 \mathrm{mmHg})$ with mean differences respectively of $+4.4 \mathrm{mmHg}$ $(95 \% \mathrm{CL}+0.3$ to +8.5$)$ and $+4.6 \mathrm{mmHg}(+0.7$ to +8.6$)$ for the systolic and diastolic readings. The spastic and flaccid subgroups did not differ in terms of age, sex, power, wasting or time from last stroke.

Stratification for the other measured characteristics (sex, age, hemiplegic side, time since stroke, power or upper-arm circumference) revealed no

Table I Mean (and standard deviation) of systolic blood pressure readings $(\mathrm{mmHg})$ for all patients and sub-groups

\begin{tabular}{|c|c|c|c|c|}
\hline & $\mathbf{n}$ & Normal arm & Hemiplegic arm & $\mathbf{P}$ \\
\hline All & 103 & $137.5(25.2)$ & $136.4(25.6)$ & 0.60 \\
\hline \multicolumn{5}{|l|}{ Sex } \\
\hline Female & 65 & $137.4(23.8)$ & $137.3(24.5)$ & 0.99 \\
\hline Male & 37 & $136.7(27.1)$ & $134.1(27.7)$ & 0.20 \\
\hline \multicolumn{5}{|c|}{ Age (years) } \\
\hline$\leqslant 70$ & 25 & $143.7(30.5)$ & $145.1(31.3)$ & 0.63 \\
\hline $71-80$ & 44 & $133.7(23.4)$ & $130.2(22.6)$ & 0.09 \\
\hline$>80$ & 34 & $138.0(22.8)$ & $138.0(23.4)$ & 0.98 \\
\hline \multicolumn{5}{|c|}{ Hemiplegic side } \\
\hline Left & 49 & $141.9(25.1)$ & $141.4(26.7)$ & 0.77 \\
\hline Right & 54 & $133.6(24.7)$ & $131.9(24.1)$ & 0.61 \\
\hline \multicolumn{5}{|c|}{$\begin{array}{l}\text { Time since stroke } \\
\text { (weeks) }\end{array}$} \\
\hline$\leqslant 6$ & 44 & $136.5(25.5)$ & $135.4(26.2)$ & 0.62 \\
\hline $7-12$ & 28 & $139.1(24.6)$ & $134.1(26.0)$ & 0.02 \\
\hline$>12$ & 31 & $137.6(25.9)$ & $140.0(25.1)$ & 0.65 \\
\hline \multicolumn{5}{|l|}{ Tone } \\
\hline Flaccid & 56 & $140.2(22.2)$ & $134.5(22.2)$ & 0.0005 \\
\hline Normal & 6 & $148.0(13.3)$ & 145.8 (13.7) & 0.67 \\
\hline Spastic & 41 & $132.4(29.3)$ & $138.0(30.7)$ & 0.01 \\
\hline \multicolumn{5}{|l|}{ Power } \\
\hline 0 & 45 & $135.1(24.5)$ & $135.4(23.2)$ & 0.87 \\
\hline $1-2$ & 35 & $144.8(26.0)$ & $141.9(27.8)$ & 0.15 \\
\hline $3-4$ & 23 & $131.3(23.4)$ & $130.1(26.2)$ & 0.71 \\
\hline \multicolumn{5}{|c|}{$\begin{array}{l}\text { Mid upper-arm } \\
\text { circumference } \\
\text { (MUAC)* }\end{array}$} \\
\hline $\mathbf{N}=\mathbf{H}$ & 53 & $135.9(25.5)$ & $135.2(25.0)$ & 0.70 \\
\hline $\mathbf{N}<\mathbf{H}$ & 20 & $138.2(23.3)$ & $135.6(19.8)$ & 0.53 \\
\hline $\mathbf{N}>\mathbf{H}$ & 30 & $138.3(28.5)$ & $142.4(28.6)$ & 0.12 \\
\hline
\end{tabular}

${ }^{*} \mathrm{~N}<\mathrm{H}$.... MUAC of paretic arm greater by $\geqslant 1 \mathrm{~cm} ; \mathrm{N}>\mathrm{H}$.... MUAC of unaffected arm greater by $\geqslant 1 \mathrm{~cm}$. 
Table II Mean (and standard deviation) of diastolic blood pressure readings $(\mathrm{mmHg})$ for all patients and sub-groups

\begin{tabular}{|c|c|c|c|c|}
\hline & $\mathrm{n}$ & Normal arm & Hemiplegic arm & $\mathbf{P}$ \\
\hline All & 103 & $72.7(13.4)$ & $71.6(14.6)$ & 0.63 \\
\hline \multicolumn{5}{|l|}{ Sex } \\
\hline Female & 65 & $72.4(12.6)$ & $72.3(13.4)$ & 0.99 \\
\hline Male & 37 & $72.7(14.5)$ & $70.6(16.7)$ & 0.19 \\
\hline \multicolumn{5}{|c|}{ Age (years) } \\
\hline$\leqslant 70$ & 25 & $77.0(30.5)$ & $76.9(17.1)$ & 0.98 \\
\hline $71-80$ & 44 & 71.4 (12.8) & 69.4 (12.9) & 0.18 \\
\hline$>80$ & 34 & $71.3(11.6)$ & $71.2(13.2)$ & 0.97 \\
\hline \multicolumn{5}{|c|}{ Hemiplegic side } \\
\hline Left & 49 & $73.6(14.9)$ & 72.4 (16.7) & 0.52 \\
\hline Right & 54 & $72.0(11.8)$ & 70.9 (12.6) & 0.54 \\
\hline \multicolumn{5}{|c|}{$\begin{array}{l}\text { Time since stroke } \\
\text { (weeks) }\end{array}$} \\
\hline$\leqslant 6$ & 44 & $72.7(13.6)$ & $69.8(11.0)$ & 0.14 \\
\hline $7-12$ & 28 & $71.1(11.6)$ & $71.0(11.8)$ & 0.94 \\
\hline$>12$ & 31 & 74.3 (14.6) & $74.6(20.4)$ & 0.90 \\
\hline \multicolumn{5}{|l|}{ Tone } \\
\hline Flaccid & 56 & $74.2(13.4)$ & $68.2(11.7)$ & $<0.0001$ \\
\hline Normal & 6 & $74.3(4.0)$ & $76.0(8.4)$ & 0.50 \\
\hline Spastic & 41 & $70.5(15.3)$ & 75.8 (17.4) & 0.02 \\
\hline \multicolumn{5}{|l|}{ Power } \\
\hline 0 & 45 & $70.2(13.8)$ & $67.8(13.9)$ & 0.31 \\
\hline $1-2$ & 35 & $78.4(13.0)$ & 77.5 (15.6) & 0.73 \\
\hline $3-4$ & 23 & $69.0(10.2)$ & $69.2(10.8)$ & 0.92 \\
\hline \multicolumn{5}{|c|}{$\begin{array}{l}\text { Mid upper-arm } \\
\text { circumference } \\
\text { (MUAC)* }\end{array}$} \\
\hline $\mathbf{N}=\mathbf{H}$ & 53 & $70.2(12.4)$ & $72.8(13.3)$ & 0.11 \\
\hline $\mathrm{N}<\mathrm{H}$ & 20 & $76.2(18.7)$ & $70.6(14.4)$ & 0.16 \\
\hline $\mathrm{N}>\mathrm{H}$ & 30 & $70.0(15.6)$ & 73.8 (13.4) & 0.03 \\
\hline
\end{tabular}

*see Table I.

significant differences in blood pressure between the arms.

\section{Discussion}

Early studies reported large differences in blood pressure between arms even in normal young subjects. ${ }^{9,10}$ More recent research has not confirmed this, and has highlighted methodological problems in the earlier studies which the design of this study overcomes. ${ }^{11,12}$ To make the findings generally applicable, the standard technique of cuff sphygmomanometer and stethoscope was used, although this does make simultaneous readings in the two arms impossible. However, the taking of repeated groups of readings allowed the comparison of the differences in blood pressure found between the arms and that caused by variation in blood pressure over time in the same arm.

The main finding of this study was a clinically significant difference in measured blood pressure between the normal and hemiplegic arms of stroke patients, with the discrepancy greater than $10 \mathrm{mmHg}$ in over $50 \%$ of patients. Other research has observed this finding but, although some have speculated that it is caused by changes in tone, $e^{3,4}$ this had remained unproven. Using a sphygmomanometer for indirect blood pressure measurement, the reduction in muscle tone in a flaccid arm was associated with a lower reading in $72 \%$ of cases. The increased compressibility of hypotonic muscle and easier occlusion of the brachial artery by the cuff could explain this finding.

The association of a spastic arm with a higher reading in $71 \%$ of patients lends support to this hypothesis, as does the absence of any difference in the other parameters recorded to explain the $\tilde{o}$ disparity between the spastic and flaccid subgroups.

This study demonstrates that indirect blood 0 pressure measurement in a hemiplegic arm is often inaccurate and is probably the result of changes in $\stackrel{?}{?}$ muscle tone. Therefore recordings of blood pres- $\square$ sure should always be made using the unaffected arm. 


\section{References}

1. Sacco, R.L., Foulkes, M.A., Mohr, J.P. et al. Determinants of early recurrence of cerebral infarction. Stroke 1989, 20: 983-989.

2. Beevers, D.G., Hamilton, M., Fairman, M.J. et al. Antihypertensive treatment and the course of established cerebrovascular disease. Lancet 1973, 1: 1407-1409.

3. Mulley, G.P. Practical Management of Stroke. Croom Helm, London, 1985.

4. Yagi, S., Ichikawa, S., Sakamaki, T. et al. Blood pressure in the paretic arms of patients with stroke (letter). $N$ Engl J Med 1986, 315: 836

5. Alvarez, A.S., McNair, D., Wildman, J. \& Hewson, J.W. Unilateral clubbing of the finger nails in patients with hemiplegia. Geront Clin 1975, 17: 1-6.

6. Bucy, P.C. Vasomotor changes associated with paralysis of cerebral origin. Arch Neurol Psychiat 1935, 33: 30-52.

7. Bickerstaff, E.R. Neurological Examination in Clinical Practice, 3rd ed. Blackwell Scientific Publications, Oxford, p. 118.
8. Petrie, J.C., O'Brien, E.T., Littler, W.A. et al. Recommendations on blood pressure measurement by a working party of the British Hypertension Society. Br Med J 1986, 293: 611-615.

9. Rueger, M.J. Blood pressure variations in the two arms. Ann Intern Med 1951, 5: 1023-1027.

10. Southby, R. Some clinical observations on blood pressure and their practical application with special reference to variation of blood pressure readings in the two arms. Med $J$ Aust 1935, 2: 569-580.

11. Hashimoto, F., Hunt, W.C. \& Hardy, L. Differences between right and left arm blood pressures in the elderly. West $\mathrm{J}$ Med 1984, 141: 189-192.

12. Goldhill, D.R. Bilateral simultaneous indirect blood pressure measurements. Cardiol Res 1986, 20: 774-777. 